\title{
3 Research Square \\ Development and Validation of Prognostic Nomogram for Patients With Small Intestinal Neuroendocrine Carcinoma
}

\section{Guangrong Lu}

Wenzhou Medical University Second Affiliated Hospital

\section{Limin Wu}

Wenzhou Medical College Second Affiliated Hospital: Wenzhou Medical University Second Affiliated Hospital

Jiajia Li

Wenzhou Medical College Second Affiliated Hospital: Wenzhou Medical University Second Affiliated Hospital

Yushan Xia

Wenzhou Medical College - Chashan Campus: Wenzhou Medical University

Xuchao Zhang

Wenzhou Medical College: Wenzhou Medical University

\section{Yuning Shi}

Wenzhou Medical College: Wenzhou Medical University

Lili Li ( $\sim 15088943401 @ 126 . c o m$ )

Departments of Radiation Oncology and Chemotherapy, The First Affiliated Hospital of Wenzhou Medical University, Wenzhou, China. https://orcid.org/0000-0002-6806-7872

\section{Research article}

Keywords: Small intestinal neuroendocrine carcinoma, overall survival, cancer-specific survival, nomogram, AJCC stage, prognosis

Posted Date: October 8th, 2020

DOI: https://doi.org/10.21203/rs.3.rs-77420/v1

License: (1) This work is licensed under a Creative Commons Attribution 4.0 International License. Read Full License 


\section{Abstract}

Small intestinal neuroendocrine carcinomas (SI NECS) are diagnosed very rarely, and the prognosis is extremely poor due to the metastatic disease of most patients at the time of diagnosis. This study aimed to establish nomogram models for prognostic evaluation of SI NEC in both overall survival (OS) and cancer-specific survival (CSS). Patients diagnosed with SI NEC between 2010 and 2015 were retrieved from the Surveillance, Epidemiology, and End Results (SEER) database and further randomly divided into the training and validating cohorts at a ratio of 7:3. Univariate and multivariate cox analysis was conducted to determine significant variables for construction of nomogram. The performance of the nomogram models were then assessed by concordance index (C-index), calibration plot and the area receiver operating characteristic (ROC) curve (AUC). A total of 1110 patients were retrospectively selected from the SEER database. Multivariate models revealed that age, tumor grade, American Joint Committee for Cancer (AJCC) stage, surgery and chemotherapy all showed a significant association with OS and CSS. The discrimination of nomogram for OS prediction was superior to that of the 7th AJCC Tumor-Node-Metastasis (TNM) staging system (C-index $=0.798,95 \% \mathrm{Cl}, 0.762-0.833$ vs 0.623 , $95 \% \mathrm{Cl}, 0.580-0.666, \mathrm{P}<0.001)$. Similar results were also observed in CSS nomogram. Well-corresponded calibration plots were noticed using the nomograms. The comparisons of AUC values showed that the established nomograms exhibited better discrimination power than 7th TNM staging system for OS and CSS prediction. In conclusion, we have successfully established novel nomograms for predicting OS and CSS in patients with SI NEC, which can assist clinicians in making predictions about individual patient survival and provide improved treatment strategies.

\section{Introduction}

Gastrointestinal tract neuroendocrine tumors are currently classified into two main categories, well differentiated and poorly differentiated, also named grade (G)1/G2 and G3, respectively [1]. Poorly differentiated neuroendocrine tumors with high-grade histology (grade 3/G3), a mitotic count $>20$, or a Ki-67 index of $>20 \%$ represent very aggressive malignancies with high proclivity for metastatic dissemination, also known as neuroendocrine carcinomas (NEC) according to the World Health Organization (WHO) classification[2, 3]. Gastrointestinal tract neuroendocrine carcinomas (GI-NECs) are rare malignancies, the majority of which are metastatic at the time of diagnosis and have a poor prognosis [4-6]. They are mainly located in the pancreas, esophagus, ampulla of Vater, and large bowel but rarely in the intestine [7-10]. Although the biology and clinical behavior of these tumors are unique, treatment directions are usually extrapolated from the guidelines of small-cell lung cancer [11]. Long-term survival for patients with metastatic high grade GI-NECs remain poor. A previous analysis of 4054 poorly differentiated NECs indicated a median survival of 34 months for patients with localized disease, 14 months for patients with regional disease, and 5 months for patients with distant disease[12].

To date, very limited literatures have been published on the survival and prognosis of small intestinal neuroendocrine carcinomas (SI NECS). Chintan P. Shah et al.[13] reported that surgery for the primary tumor significantly improved 5-year survival in metastatic small intestinal neuroendocrine tumor regardless of tumor size, grade, or histology. Moreover, age $>50$ years, duodenal location, tumor size $>2 \mathrm{~cm}$, poor differentiation of the tumor and not receiving any surgical intervention were found to be poor prognostic factors. Another two studies demonstrated that poor performance status, high proliferation rate, elevated lactate dehydrogenase, and thrombocytosis at baseline were negative prognostic markers for GI-NECs[8, 10]. However, in view of these 
unconsolidated factors, no studies have incorporated them to accurately predict the outcomes of patients with SI NECs.

Nomogram, which has been one of the most widely used statistic methods in clinical investigations, can calculate the probability of a clinical event by considering the prognostic weight of each factor. Featured by visual and mathematical advantages, nomogram facilitates clinical decision making, risk stratification and individualized treatment. In addition, many studies have indicated that a nomogram is superior to the American Joint Committee for Cancer (AJCC) Tumor-Node-Metastasis (TNM) staging system in predicting the survival of cancer patients[14, 15]. Therefore, this study aimed to identify the prognostic factors and to develop nomograms to investigate overall survival (OS) and cancer-specific survival (CSS) in patients with SI NECs.

\section{Materials And Methods}

\section{Data retrieved from SEER}

We screened patient data from a cohort of SI NEC patients in the Surveillance, Epidemiology, and End Results (SEER) registry database of the National Cancer Institute using SEER*Stat software (version. 8.3.5). The SEER database covers about $28 \%$ of the US population and contains a large amount of evidence-based medical information [16]. No local ethical approval or declaration was required for this study. Because all of the data used in this study were obtained from the SEER database with a publicly available method. The patients were identified using the following SEER variables: Site Recode International Classification of Diseases for Oncology, third Edition (ICD-0-3) / WHO 2008 classification (small intestine) and "histology code 8246/3 (NEC). The TNM staging data were retrieved based on the code 'derived AJCC TNM stage group 7th ed' (hereinafter referred to as the AJCC stage), which was published in 2010, and so the allowable year of diagnosis ranged from 2010 to 2015 . The exclusion criteria mainly included (1) cases identified at autopsy or by death certificate, (2) missing or incomplete information of follow-up, (3) diagnosis made based on only clinical suspicion without radiological, laboratory or microscopic confirmation, (4) death reported within the first month of diagnosis. All included SI NECs were randomly assigned into training set and validation set at a ratio of 7:3.

Clinical variables of SI NECs

Clinical and pathological variables, including age, sex, race, marital status, insurance status, year of diagnosis, histology grade, primary site, AJCC stage, treatment status (for surgery, chemotherapy, and radiotherapy), and survival time, were collected and analyzed. OS and CSS were defined as the duration from the date of diagnosis to the last follow-up or death due to all causes or SI NEC, respectively.

Construction and validation of nomogram model

Fisher's exact or Chi-square tests for categorical variables and Student's t-test for continuous variables were used for the comparison of baseline characteristics. Univariate and multivariate analyses were performed to determine independent prognostic variables. Then, nomograms to predict the 3- and 5-year OS and CSS rates were constructed using the results of the multivariate analyses. The performance of the nomograms were measured by Harrell's concordance index (C-index) and the area receiver operating characteristic (ROC) curve (AUC). The calibration curves were assessed for the comparison between the nomogram-predicted probability and the observed outcome using a 45-degee line as an optimal model. Furthermore, the nomograms were also compared 
to the 7th TNM stage in terms of C-index. All the statistical analyses were performed using $\mathrm{R}$ version 3.4.2 software (The R Foundation for Statistical Computing, Vienna, Austria. http:// www.r-project.org). A two tailed p < 0.05 was considered statistically significant.

\section{Results}

\section{Patient Characteristics}

A total of 1110 SI NECs were identified retrospectively from the SEER database, of which 778 cases were randomly assigned to the training set while 332 were into validation set (Figure 1). In the training cohort, the majority of patients were over 60 years old (59.4\%), male (52.2\%), white (80.2\%), married (59.9\%) and insured (86.1\%). Moreover, Ileum was the most common primary site, and grade I and II of tumor differentiation degree accounted for 77.8 and $18 \%$, respectively of all the cases. $30.9 \%$ of the patients were in AJCC stage IV and a large proportion of the patients received surgery (93.4\%). The chemotherapy data were no/unknown for most of the patients (90\%). Patients were comparable with respect to all clinicopathological characteristics between the training set and validation set in this study (Table 1).

Univariate and Multivariate Analyses of Factors for OS and CSS

In the univariate analysis, age, marital status, insurance, tumor grade, primary site, AJCC stage, surgery, chemotherapy and radiotherapy were significantly associated with OS (Table 2). However, only age, tumor grade, AJCC stage, surgery and chemotherapy were identified as significantly associated with OS in the multivariate analysis. Moreover, in CSS analysis, age, marital status, tumor grade, AJCC stage, surgery, chemotherapy and radiotherapy were identified by univariate analysis. Then, only age, tumor grade, AJCC stage, surgery and chemotherapy were significantly identified in the multivariate analysis. Radiotherapy failed to act as a risk factor for both OS and CSS.

Construction and validation of nomograms for OS and CSS

All the significant and independent prognostic factors of OS and CSS were integrated into the nomograms. Figure 2 illustrated the predictive nomograms established for the 3-, and 5-year OS and CSS rates in the training set. By adding up the scores for each selected variable, a patient's probability of individual survival can be easily calculated. The nomogram for OS prediction demonstrated good accuracy, with a C-index of 0.798 ( $95 \%$ Cl, 0.7620.833) for the training cohort. Additionally, the C-index of the nomogram based on internal validation cohort was also higher than that based on the 7th TNM stage (Table 3). Calibration plots of 3-, and 5-year OS probabilities confirmed optimal agreement between the nomogram-predicted survival and actual observations in both the training and internal validation sets (Figure 3). In terms of CSS prediction, relatively good nomogram accuracy for CSS prediction was observed with a C-index of $0.874(95 \% \mathrm{Cl}, 0.845-0.903)$ for the training cohort. The calibration plots also showed high agreement between CSS prediction and the actual survival for training and internal validation cohort (Figure 4). Furthermore, the nomogram based on internal validation cohort had significantly higher value of C-index compared with the 7th TNM staging system, showing more powerful efficiency of discrimination for CSS prediction (Table 3).

Comparison of the Values of Area Under the ROC Curve 
The AUC values of the nomograms for predicting the 3-, and 5-year OS and CSS rates were shown in Figure $5 \& 6$. For the training cohort, the AUC values of the nomogram for predicting the 3-, and 5-year OS rates were 0.809 and 0.801 , and 0.64 and 0.624 for the 7th TNM staging system, respectively (Table 4). As for the prediction of the 3-, and 5-year CSS rates, higher AUC values were also observed for the nomogram compared with the 7th TNM staging system. Similar results were demonstrated in the internal validation set.

\section{Discussion}

SI NECs are diagnosed very rarely, and the prognosis is extremely poor due to the metastatic disease of most patients at the time of diagnosis. In recent years, nomograms have been widely used to predict individualized survival outcomes for cancer patients [17-21]. The rarity of SI NECs increases the practicality of using a simple nomogram to predict patient survival in clinical decision-making. Although the AJCC staging system is helpful in determining the prognosis of SI NEC patients (17), it ignores some important risk factors such as age, grade, and surgery. In the present study, we constructed well-calibrated prognostic nomograms to predict OS and CSS in patients with SI NECs. Furthermore, superior discriminative power of the nomograms was confirmed by the higher AUC values in comparison with the 7th AJCC staging system in both the training and validation sets.

There are very few literatures on SI NECs, most of which are case reports. Instead, many studies have focused on the survival and prognosis of neuroendocrine carcinoma of digestive tract[22-24]. The proposed nomograms in our study included several independent prognostic factors-age, tumor grade, AJCC stage, surgery and chemotherapy-that were identified by applying both forward and backward stepwise selection methods in a Cox regression model. A previous study [13] indicated that age, poor differentiation of the tumor and surgery were significantly independent factors for patients with metastatic small intestinal neuroendocrine tumor, which was in line with our results. Chemotherapy is the main treatment method for GI-NECs, and it has also been reported that radiotherapy can play a part in improving survival outcomes for these patients[23]. Our study did not find this association, the possible reason being that the current SEER data on radiotherapy was potentially biased because of its retrospective nature. Moreover, our research demonstrated that patients receiving chemotherapy had a worse survival prognosis. One explanation might be that only a small proportion of patients received chemotherapy in our study, while the data on chemotherapy was unavailable (no/unknown) in the remaining patients. Thus, incorporating these variables will be a major part of our future research.

Considering the scarcity of SI NEC, a prospective study with a sufficient sample size will not be practically possible. Therefore, a retrospective study with a longer patient recruitment period and sufficient sample size can provide an evidence base with strong statistical efficacy. So far, SEER database has provided the largest sample size for various types of cancers. Competing risk nomograms based on SEER have been developed for several cancers, including esophageal cancer, gastric adenocarcinoma and lung cancer[17, 25, 26]. To our knowledge, this is the first attempt to establish competitive risk nomograms to predict OS and CSS in SI NEC patients. The combination of main factors of traditional staging systems and other tumor-related indicators, such as age, tumor grade and surgery, contributed to the better discrimination power in predicting both OS and CSS compared with 7th edition TNM staging system, which was shown by the comparisons of C-indexes and AUC values. Wellcorresponded calibration plots were also observed using the nomograms. Moreover, the nomograms, which were comprised of a few easily acquired predictors, could help clinicians quantify the risks of cancer specific death and thereby design appropriate treatment strategies for individual patients. 
There were several limitations in our study that should be considered. First, the current study had a retrospective research type design with inherent biases. Second, patient data were collected from the SEER database, in which chemotherapy status was reported only as either "yes" or "no/unknown." Lack of detailed chemotherapy information might have affected the obtained results. Third, the results of this study would be more significant if the nomogram model could be externally validated by another independent, large and high-quality cohort, which would further testify the accuracy of our model. Despite all these limitations, our study remains the largest population-based SI NEC study and provides an instructive and efficient model of SI NEC prognosis.

In conclusion, we have developed and validated novel nomograms for predicting OS and CSS in patients with SI NEC. The nomograms were simple and efficient, and exhibited superior survival predictive ability compared to the AJCC staging system. These tools can assist clinicians in making predictions about individual patient survival and provide improved treatment strategies.

\section{Declarations}

\section{Data Availability Statement}

The datasets generated for this study are available on request to the corresponding author.

\section{Author Contributions}

Lili Li was responsible for conception, design, quality control of this study, reviewed, and edited the manuscript. Guangrong Lu, Limin Wu performed data extraction, statistical analyses, and were major contributors in writing the manuscript. Jiajia Li, Yushan Xia, Xuchao Zhang and Yuning Shi participated in data extraction and statistical analyses. All authors have read and approved the final version of the manuscript.

\section{Funding}

None.

Conflict of Interest: The authors declare that the research was conducted in the absence of any commercial or financial relationships that could be construed as a potential conflict of interest.

\section{References}

1. Nagtegaal ID, Odze RD, Klimstra D, Paradis V, Rugge M, Schirmacher P, et al. The 2019 WHO classification of tumours of the digestive system. Histopathology. 2020; 76: 182-8.

2. Oberg K, Castellano D. Current knowledge on diagnosis and staging of neuroendocrine tumors. Cancer metastasis reviews. 2011; 30 Suppl 1: 3-7.

3. Chai SM, Brown IS, Kumarasinghe MP. Gastroenteropancreatic neuroendocrine neoplasms: selected pathology review and molecular updates. Histopathology. 2018; 72: 153-67.

4. Verbeke CS. Endocrine tumours of the pancreas. Histopathology. 2010; 56: 669-82.

5. Lee SS, Lee JL, Ryu MH, Chang HM, Kim TW, Kim WK, et al. Extrapulmonary small cell carcinoma: single center experience with 61 patients. Acta oncologica. 2007; 46: 846-51.

6. Galanis E, Frytak S, Lloyd RV. Extrapulmonary small cell carcinoma. Cancer. 1997; 79: 1729-36. 
7. Brenner B, Tang LH, Klimstra DS, Kelsen DP. Small-cell carcinomas of the gastrointestinal tract: a review. Journal of clinical oncology : official journal of the American Society of Clinical Oncology. 2004; 22: $2730-9$.

8. Sorbye H, Welin S, Langer SW, Vestermark LW, Holt N, Osterlund P, et al. Predictive and prognostic factors for treatment and survival in 305 patients with advanced gastrointestinal neuroendocrine carcinoma (WHO G3): the NORDIC NEC study. Annals of oncology : official journal of the European Society for Medical Oncology. 2013; 24: 152-60.

9. Brenner B, Shah MA, Gonen M, Klimstra DS, Shia J, Kelsen DP. Small-cell carcinoma of the gastrointestinal tract: a retrospective study of 64 cases. British journal of cancer. 2004; 90: 1720-6.

10. Yamaguchi T, Machida N, Morizane C, Kasuga A, Takahashi H, Sudo K, et al. Multicenter retrospective analysis of systemic chemotherapy for advanced neuroendocrine carcinoma of the digestive system. Cancer science. 2014; 105: 1176-81.

11. Garcia-Carbonero R, Sorbye H, Baudin E, Raymond E, Wiedenmann B, Niederle B, et al. ENETS Consensus Guidelines for High-Grade Gastroenteropancreatic Neuroendocrine Tumors and Neuroendocrine Carcinomas. Neuroendocrinology. 2016; 103: 186-94.

12. Yao JC, Hassan M, Phan A, Dagohoy C, Leary C, Mares JE, et al. One hundred years after "carcinoid": epidemiology of and prognostic factors for neuroendocrine tumors in 35,825 cases in the United States. Journal of clinical oncology : official journal of the American Society of Clinical Oncology. 2008; 26: 3063-72.

13. Shah CP, Mramba LK, Bishnoi R, Unnikrishnan A, Duff JM, Chandana SR. Survival trends of metastatic small intestinal neuroendocrine tumor: a population-based analysis of SEER database. Journal of gastrointestinal oncology. 2019; 10: 869-77.

14. Chen S, Lai Y, He Z, Li J, He X, Shen R, et al. Establishment and validation of a predictive nomogram model for non-small cell lung cancer patients with chronic hepatitis $B$ viral infection. Journal of translational medicine. 2018; 16: 116.

15. Roberto M, Botticelli A, Strigari L, Ghidini M, Onesti CE, Ratti M, et al. Prognosis of elderly gastric cancer patients after surgery: a nomogram to predict survival. Medical oncology. 2018; 35: 111.

16. Zeng C, Wen W, Morgans AK, Pao W, Shu XO, Zheng W. Disparities by Race, Age, and Sex in the Improvement of Survival for Major Cancers: Results From the National Cancer Institute Surveillance, Epidemiology, and End Results (SEER) Program in the United States, 1990 to 2010. JAMA oncology. 2015; 1: 88-96.

17. Tang X, Zhou X, Li Y, Tian X, Wang Y, Huang M, et al. A Novel Nomogram and Risk Classification System Predicting the Cancer-Specific Survival of Patients with Initially Diagnosed Metastatic Esophageal Cancer: A SEER-Based Study. Annals of surgical oncology. 2019; 26: 321-8.

18. Guo LW, Jiang LM, Gong Y, Zhang HH, Li XG, He M, et al. Development and validation of nomograms for predicting overall and breast cancer-specific survival among patients with triple-negative breast cancer. Cancer management and research. 2018; 10: 5881-94.

19. Dai D, Jin H, Wang X. Nomogram for predicting survival in triple-negative breast cancer patients with histology of infiltrating duct carcinoma: a population-based study. American journal of cancer research. 2018; 8: $1576-85$.

20. Wu Q, Wang WJ, Huang YQ, Fang SY, Guan YJ. Nomograms for estimating survival in patients with liver-only colorectal metastases: A retrospective study. International journal of surgery. 2018; 60: 1-8.

21. Jiang S, Zhao R, Li Y, Han X, Liu Z, Ge W, et al. Prognosis and nomogram for predicting postoperative survival of duodenal adenocarcinoma: A retrospective study in China and the SEER database. Scientific reports. 2018; 

8: 7940

22. Thomas KEH, Voros BA, Boudreaux JP, Thiagarajan R, Woltering EA, Ramirez RA. Current Treatment Options in Gastroenteropancreatic Neuroendocrine Carcinoma. The oncologist. 2019; 24: 1076-88.

23. Sorbye H, Strosberg J, Baudin E, Klimstra DS, Yao JC. Gastroenteropancreatic high-grade neuroendocrine carcinoma. Cancer. 2014; 120: 2814-23.

24. Alese OB, Jiang R, Shaib W, Wu C, Akce M, Behera M, et al. High-Grade Gastrointestinal Neuroendocrine Carcinoma Management and Outcomes: A National Cancer Database Study. The oncologist. 2019; 24: 91120.

25. Wang CY, Yang J, Zi H, Zheng ZL, Li BH, Wang Y, et al. Nomogram for predicting the survival of gastric adenocarcinoma patients who receive surgery and chemotherapy. BMC cancer. 2020; 20: 10.

26. Shang X, Yu H, Lin J, Li Z, Zhao C, Sun J, et al. A Novel Nomogram including AJCC Stages Could Better Predict Survival for NSCLC Patients Who Underwent Surgery: A Large Population-Based Study. Journal of oncology. 2020; 2020: 7863984.

\section{Tables}




\begin{tabular}{|c|c|c|c|c|}
\hline Variables & Total $(\mathrm{n}=1110)$ & Training Cohort(n=778) & Validation Cohort( $\mathrm{n}=332)$ & $\mathrm{P}$ \\
\hline Age $\$ year囚n(\%) & & & & 0.344 \\
\hline$\otimes 60$ & $461 \rrbracket 41.5 \rrbracket$ & $316 \varangle 40.6 \rrbracket$ & $145 \rrbracket 43.7 \rrbracket$ & \\
\hline$\geq 60$ & $649 \llbracket 58.5 \rrbracket$ & $462 \rrbracket 59.4 \rrbracket$ & 187ه56.3区 & \\
\hline Sex n(\%) & & & & 0.505 \\
\hline Female & $538(48.9)$ & $372 ه 47.8 \rrbracket$ & $166 \rrbracket 50 \rrbracket$ & \\
\hline Male & $572(51.1)$ & $406 \varangle 52.2 \rrbracket$ & $166 \rrbracket 50 \rrbracket$ & \\
\hline Race n(\%) & & & & 0.452 \\
\hline Black & $186(16.8)$ & 137凶17.6ه & $49 \rrbracket 14.8 \rrbracket$ & \\
\hline White & $901(81.2)$ & $624 \llbracket 80.2 \rrbracket$ & $277 \rrbracket 83.4 \rrbracket$ & \\
\hline Others & $23 \rrbracket 2.0 \rrbracket$ & $17 \rrbracket 2.2 \rrbracket$ & $6 \rrbracket 1.8 \rrbracket$ & \\
\hline Marital status n(\%) & & & & 0.629 \\
\hline Married & $670 \rrbracket 60.4 \rrbracket$ & $466 \rrbracket 59.9 \rrbracket$ & $204 \llbracket 61.4 \rrbracket$ & \\
\hline Unmarried & $440 \rrbracket 39.6 \rrbracket$ & $312 \varangle 40.1 \rrbracket$ & $128 \llbracket 38.6 \rrbracket$ & \\
\hline Year of diagnosis n(\%) & & & & 0.566 \\
\hline 2010 & 185囚16.7ه & 123凶15.8ه & $62 \bowtie 18.7 \rrbracket$ & \\
\hline 2011 & 217®19.6》 & $156 \llbracket 20.1 \rrbracket$ & $61 \rrbracket 18.4 \rrbracket$ & \\
\hline 2012 & $223 \llbracket 20.1 \rrbracket$ & 149凶19.2ه & $74 \rrbracket 22.3 \rrbracket$ & \\
\hline 2013 & $268 \rrbracket 24.1 \rrbracket$ & 196囚25.2】 & $72 \rrbracket 21.7 \rrbracket$ & \\
\hline 2014 & 120冈10.8\ & $85 \rrbracket 10.9 \rrbracket$ & $35 \rrbracket 10.5 \rrbracket$ & \\
\hline 2015 & 97ه8.7区 & $69 \otimes 8.8 \rrbracket$ & $28 \varangle 8.4 \rrbracket$ & \\
\hline Insurance n(\%) & & & & 0.288 \\
\hline Insured & $955 \llbracket 86.0 \rrbracket$ & $670 \rrbracket 86.1 \rrbracket$ & $285 \llbracket 85.8 \rrbracket$ & \\
\hline Any medicaid & 103ه9.3凶 & $76 \otimes 9.8 \square$ & $27(8.2)$ & \\
\hline Uninsured & $52 \rrbracket 4.7 \rrbracket$ & $32 \otimes 4.1 \rrbracket$ & $20(6.0)$ & \\
\hline Grade n(\%) & & & & 0.389 \\
\hline I & 870冈78.4囚 & $605(77.8)$ & $265(79.8)$ & \\
\hline II & 192\17.3》 & $140(18.0)$ & $52(15.7)$ & \\
\hline III & $38 \bowtie 3.4 \rrbracket$ & $28(3.6)$ & $10(3.0)$ & \\
\hline IV & $10 \otimes 0.98$ & $5(0.6)$ & $5(1.5)$ & \\
\hline Primary site $\mathrm{n}(\%)$ & & & & 0.729 \\
\hline
\end{tabular}




\begin{tabular}{|c|c|c|c|c|}
\hline Duodenum & $172 \bigotimes 15.5 \rrbracket$ & 119(15.3) & $53(16.0)$ & \\
\hline Jejunum & $59 \rrbracket 5.3 \rrbracket$ & $41(5.3)$ & $18(5.4)$ & \\
\hline lleum & $545 \llbracket 49.1 \rrbracket$ & $382(49.1)$ & $163(49.1)$ & \\
\hline Overlapping lesion & 14ه1.3囚 & $10(1.3)$ & $4(1.2)$ & \\
\hline Small intestine, NOS & $320 \rrbracket 28.8 \rrbracket$ & $226(29.0)$ & $94(28.3)$ & \\
\hline AJCC TNM stage(7th) n(\%) & & & & 0.698 \\
\hline 1 & $94 \rrbracket 8.5 \rrbracket$ & $68(8.7)$ & $26(7.8)$ & \\
\hline$\|$ & 147囚13.2】 & 108(13.9) & $39(11.7)$ & \\
\hline III & $526 \varangle 47.4 \rrbracket$ & $362(46.5)$ & $164(49.4)$ & \\
\hline IV & $343 \llbracket 30.9 \rrbracket$ & $240(30.9)$ & 103(31.1) & \\
\hline Surgery $n(\%)$ & & & & 0.682 \\
\hline No & $75 \otimes 6.8 \rrbracket$ & $51(6.6)$ & $24(7.2)$ & \\
\hline Yes & $1035 \otimes 93.2 \rrbracket$ & 727(93.4) & $308(92.8)$ & \\
\hline Chemotherapy n(\%) & & & & 0.324 \\
\hline No/unknown & $1005 \otimes 90.5 \rrbracket$ & $700(90.0)$ & $305(91.9)$ & \\
\hline Yes & $105 \rrbracket 9.5 \rrbracket$ & $78(10.0)$ & $27(8.1)$ & \\
\hline Radiotherapy n(\%) & & & & 0.936 \\
\hline No & 1086ه97.8\ & $761(97.8)$ & $325(97.9)$ & \\
\hline Yes & $24 \bowtie 2.2 \rrbracket$ & $17(2.2)$ & $7(2.1)$ & \\
\hline
\end{tabular}

AJCC, American Joint Committee for Cancer; TNM, Tumor-Node-Metastasis.

Table 2. Univariate and multivariate analyses of survival in patients with small intestinal neuroendocrine carcinoma 


\begin{tabular}{|c|c|c|c|c|c|c|c|c|}
\hline \multirow{3}{*}{ Variables } & \multicolumn{4}{|c|}{ Overall survival } & \multicolumn{4}{|c|}{ Cancer-specific survival } \\
\hline & \multicolumn{2}{|c|}{$\begin{array}{l}\text { Univariate } \\
\text { analysis }\end{array}$} & \multicolumn{2}{|c|}{ Multivariate analysis } & \multicolumn{2}{|c|}{$\begin{array}{l}\text { Univariate } \\
\text { analysis }\end{array}$} & \multicolumn{2}{|c|}{ Multivariate analysis } \\
\hline & $\begin{array}{l}\text { log rank } \\
X^{2}\end{array}$ & $P$ & $\mathrm{HR}(95 \rrbracket \mathrm{Cl})$ & $P$ & $\begin{array}{l}\log \text { rank } \\
X^{2}\end{array}$ & $P$ & $\mathrm{HR}(95 \rrbracket \mathrm{Cl})$ & $P$ \\
\hline Sex & 3.389 & 0.066 & & & 3.643 & 0.056 & & \\
\hline Female & & & Reference & & & & Reference & \\
\hline Male & & & $\begin{array}{l}1.179(0.834- \\
1.666)\end{array}$ & 0.353 & & & $\begin{array}{l}1.249(0.815- \\
1.915)\end{array}$ & 0.308 \\
\hline Age(year) & 94.295 & 0.001 & & $\varangle 0.001$ & 50.64 & 0.001 & & $\begin{array}{l}{[} \\
0.001\end{array}$ \\
\hline$₫ 50$ & & & Reference & & & & Reference & \\
\hline $50-59$ & & & $\begin{array}{l}2.317(0.991- \\
5.420)\end{array}$ & 0.053 & & & $\begin{array}{l}2.162(0.795- \\
5.882)\end{array}$ & 0.131 \\
\hline $60-69$ & & & $\begin{array}{l}2.652(1.162- \\
6.055)\end{array}$ & 0.021 & & & $\begin{array}{l}2.972(1.126- \\
7.840)\end{array}$ & 0.028 \\
\hline $70-79$ & & & $\begin{array}{l}5.603(2.493- \\
12.593)\end{array}$ & $\otimes 0.001$ & & & $\begin{array}{l}4.587(1.749- \\
12.034)\end{array}$ & 0.002 \\
\hline$\geq 80$ & & & $\begin{array}{l}14.402(6.298- \\
32.933)\end{array}$ & 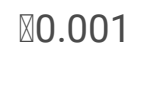 & & & $\begin{array}{l}14.452(5.374- \\
38.866)\end{array}$ & $\begin{array}{l}0.001 \\
0.01\end{array}$ \\
\hline Race & 0.857 & 0.652 & & & 2.853 & 0.240 & & \\
\hline \multicolumn{9}{|l|}{ Black } \\
\hline \multicolumn{9}{|l|}{ White } \\
\hline \multicolumn{9}{|l|}{ Others } \\
\hline Marital status & 12.558 & 0.001 & & & 5.407 & 0.020 & & \\
\hline Married & & & Reference & & & & Reference & \\
\hline Unmarried & & & $\begin{array}{l}1.371(0.968- \\
1.941)\end{array}$ & 0.075 & & & $\begin{array}{l}1.268(0.843- \\
1.907)\end{array}$ & 0.254 \\
\hline $\begin{array}{l}\text { Year of } \\
\text { diagnosis }\end{array}$ & 1.853 & 0.869 & & & 2.014 & 0.847 & & \\
\hline \multicolumn{9}{|l|}{2010} \\
\hline \multicolumn{9}{|l|}{2011} \\
\hline \multicolumn{9}{|l|}{2012} \\
\hline \multicolumn{9}{|l|}{2013} \\
\hline \multicolumn{9}{|l|}{2014} \\
\hline 2015 & & & & & & & & \\
\hline
\end{tabular}




\begin{tabular}{|c|c|c|c|c|c|c|c|c|}
\hline Insurance & 8.239 & 0.016 & & 0.052 & 3.038 & 0.219 & & \\
\hline Insured & & & Reference & & & & & \\
\hline Any medicaid & & & $\begin{array}{l}1.706(1.041- \\
2.798)\end{array}$ & 0.034 & & & & \\
\hline Uninsured & & & $\begin{array}{l}1.714(0.793- \\
3.706)\end{array}$ & 0.171 & & & & \\
\hline Grade & 120.296 & $\begin{array}{l}\square \\
0.001\end{array}$ & & $\varangle 0.001$ & 203.683 & $\begin{array}{l}\square \\
0.001\end{array}$ & & $\begin{array}{l}\square \\
0.001\end{array}$ \\
\hline 1 & & & Reference & & & & Reference & \\
\hline ॥ & & & $\begin{array}{l}1.701(1.143- \\
2.533)\end{array}$ & 0.009 & & & $\begin{array}{l}2.481(1.559- \\
3.949)\end{array}$ & $\begin{array}{l}\square \\
0.001\end{array}$ \\
\hline III & & & $\begin{array}{l}5.158(2.799- \\
9.504)\end{array}$ & $\otimes 0.001$ & & & $\begin{array}{l}9.604(5.019- \\
18.376)\end{array}$ & $\begin{array}{l}\square \\
0.001\end{array}$ \\
\hline IV & & & $\begin{array}{l}5.899(1.889- \\
18.420)\end{array}$ & 0.002 & & & $\begin{array}{l}17.130(5.285- \\
55.521)\end{array}$ & $\begin{array}{l}\square \\
0.001\end{array}$ \\
\hline Primary site & 12.528 & 0.014 & & 0.191 & 7.651 & 0.105 & & \\
\hline Duodenum & & & Reference & & & & & \\
\hline Jejunum & & & $\begin{array}{l}0.555(0.206- \\
1.498)\end{array}$ & 0.245 & & & & \\
\hline Ileum & & & $\begin{array}{l}0.664(0.389- \\
1.133)\end{array}$ & 0.133 & & & & \\
\hline $\begin{array}{l}\text { Overlapping } \\
\text { lesion }\end{array}$ & & & $\begin{array}{l}0.339(0.045- \\
2.545)\end{array}$ & 0.293 & & & & \\
\hline $\begin{array}{l}\text { Small } \\
\text { intestine, NOS }\end{array}$ & & & $\begin{array}{l}0.965(0.571- \\
1.630)\end{array}$ & 0.965 & & & & \\
\hline $\begin{array}{l}\text { AJCC TNM } \\
\text { stage(7th) }\end{array}$ & 43.184 & $\begin{array}{l}\square \\
0.001\end{array}$ & & $\varangle 0.001$ & 79.492 & $\begin{array}{l}\square \\
0.001\end{array}$ & & $\begin{array}{l}\square \\
0.001\end{array}$ \\
\hline 1 & & & Reference & & & & Reference & \\
\hline II & & & $\begin{array}{l}1.688(0.711- \\
4.005)\end{array}$ & 0.235 & & & $\begin{array}{l}4.353(0.533- \\
35.529)\end{array}$ & 0.170 \\
\hline III & & & $\begin{array}{l}1.390(0.613- \\
3.153)\end{array}$ & 0.4331 & & & $\begin{array}{l}5.226(0.704- \\
38.787)\end{array}$ & 0.106 \\
\hline IV & & & $\begin{array}{l}3.093(1.341- \\
7.132)\end{array}$ & 0.008 & & & $\begin{array}{l}16.608(2.271- \\
121.439)\end{array}$ & 0.006 \\
\hline Surgery & 45.445 & $\begin{array}{l}\square \\
0.001\end{array}$ & & & 50.299 & ${ }^{\square} 0.001$ & & \\
\hline No & & & Reference & & & & Reference & \\
\hline Yes & & & $\begin{array}{l}0.416(0.259- \\
0.669)\end{array}$ & $\varangle 0.001$ & & & $\begin{array}{l}0.340(0.201- \\
0.576)\end{array}$ & $\begin{array}{l}\square \\
0.001\end{array}$ \\
\hline Chemotherapy & 44.603 & $\begin{array}{l}\square \\
0.001\end{array}$ & & & 80.444 & 0.001 & & \\
\hline
\end{tabular}

Page 12/19 


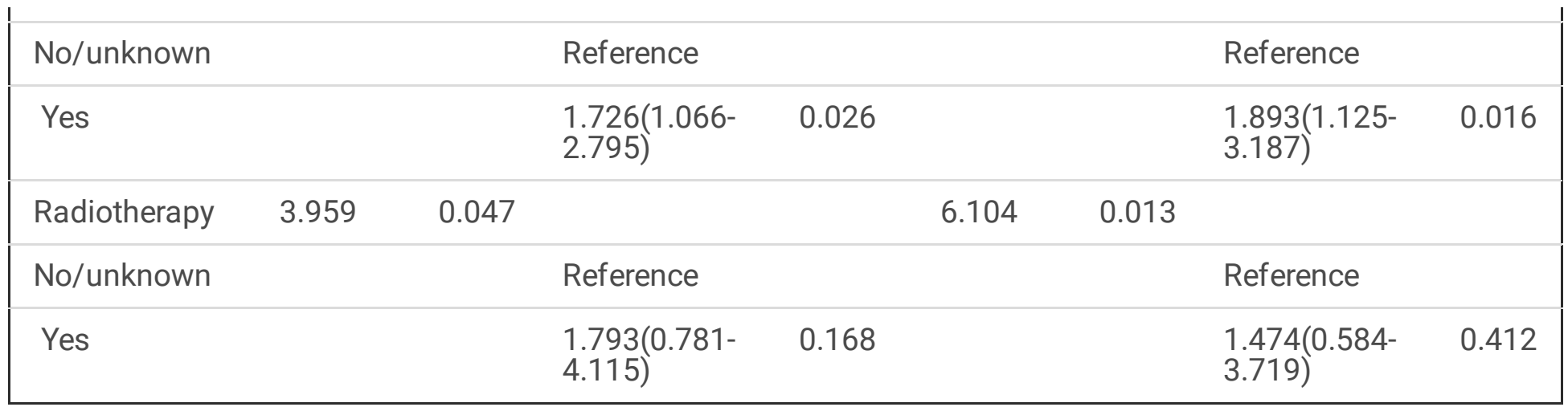

HR, hazard ratio; Cl, confidence interval; AJCC, American Joint Committee for Cancer; TNM, Tumor-NodeMetastasis.

Table 3. C-indexes for the nomograms and TNM stage systems in patients with small intestinal neuroendocrine carcinoma

\begin{tabular}{|c|c|c|c|c|c|}
\hline survival & & Training cohort & $P$ & $\begin{array}{l}\text { Internal validation } \\
\text { cohort }\end{array}$ & $\mathrm{P}$ \\
\hline \multirow[t]{2}{*}{ overall survival } & Nomogram & $\begin{array}{l}0.798 \otimes 0.762- \\
0.833 \rrbracket\end{array}$ & $\begin{array}{l}\square \\
0.001\end{array}$ & $0.754 \rrbracket 0.683-0.825 \rrbracket$ & $\otimes 0.05$ \\
\hline & $\begin{array}{l}\text { 7th TNM } \\
\text { stage }\end{array}$ & $\begin{array}{l}0.623 \rrbracket 0.580- \\
0.666 \rrbracket\end{array}$ & & $0.68 \rrbracket 0.615-0.745 \rrbracket$ & \\
\hline \multirow[t]{2}{*}{$\begin{array}{l}\text { cancer-specific } \\
\text { survival }\end{array}$} & Nomogram & $\begin{array}{l}0.874 \rrbracket 0.845- \\
0.903 \rrbracket\end{array}$ & $\begin{array}{l}\square \\
0.001\end{array}$ & $0.837 \rrbracket 0.768-0.906 \rrbracket$ & $\otimes 0.05$ \\
\hline & $\begin{array}{l}\text { 7th TNM } \\
\text { stage }\end{array}$ & $\begin{array}{l}0.704 \llbracket 0.659- \\
0.749 \rrbracket\end{array}$ & & $0.748 \rrbracket 0.681-0.815 \rrbracket$ & \\
\hline
\end{tabular}

Table 4. Comparison of AUC values between nomograms and TNM stage systems in patients with small intestinal neuroendocrine carcinoma

\begin{tabular}{|c|c|c|c|c|c|}
\hline \multicolumn{2}{|l|}{ Survival } & \multicolumn{2}{|c|}{ Training cohort } & \multicolumn{2}{|c|}{ Internal validation cohor } \\
\hline & & $\begin{array}{l}\text { 3-year } \\
\text { survival }\end{array}$ & $\begin{array}{l}\text { 5-year } \\
\text { survival }\end{array}$ & $\begin{array}{l}\text { 3-year } \\
\text { survival }\end{array}$ & $\begin{array}{l}\text { 5-year } \\
\text { survival }\end{array}$ \\
\hline \multirow[t]{2}{*}{ Overall survival } & Nomogram & 0.809 & 0.801 & 0.72 & 0.761 \\
\hline & $\begin{array}{l}\text { 7th TNM } \\
\text { stage }\end{array}$ & 0.64 & 0.624 & 0.658 & 0.646 \\
\hline \multirow{2}{*}{$\begin{array}{l}\text { Cancer-specific } \\
\text { survival }\end{array}$} & Nomogram & 0.888 & 0.871 & 0.816 & 0.829 \\
\hline & $\begin{array}{l}\text { 7th TNM } \\
\text { stage }\end{array}$ & 0.731 & 0.704 & 0.752 & 0.717 \\
\hline
\end{tabular}




\section{Figures}

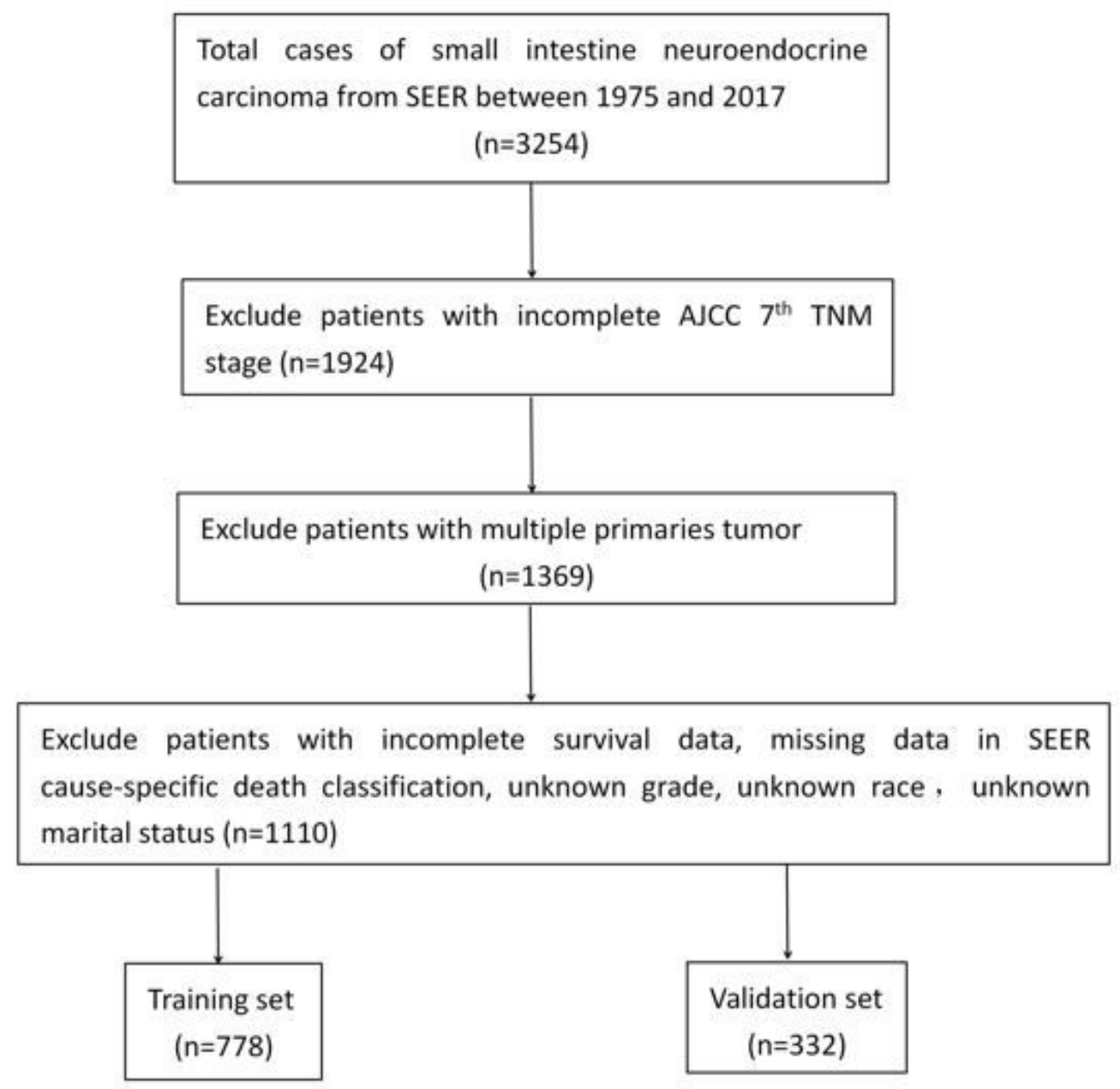

\section{Figure 1}

Flow diagram of the SI NEC patients with training and validation cohorts. SI NEC, small intestinal neuroendocrine carcinoma; AJCC, American Joint Committee on Cancer; TNM, tumor-node-metastasis; SEER, Surveillance, Epidemiology, and End Results (SEER). 
A

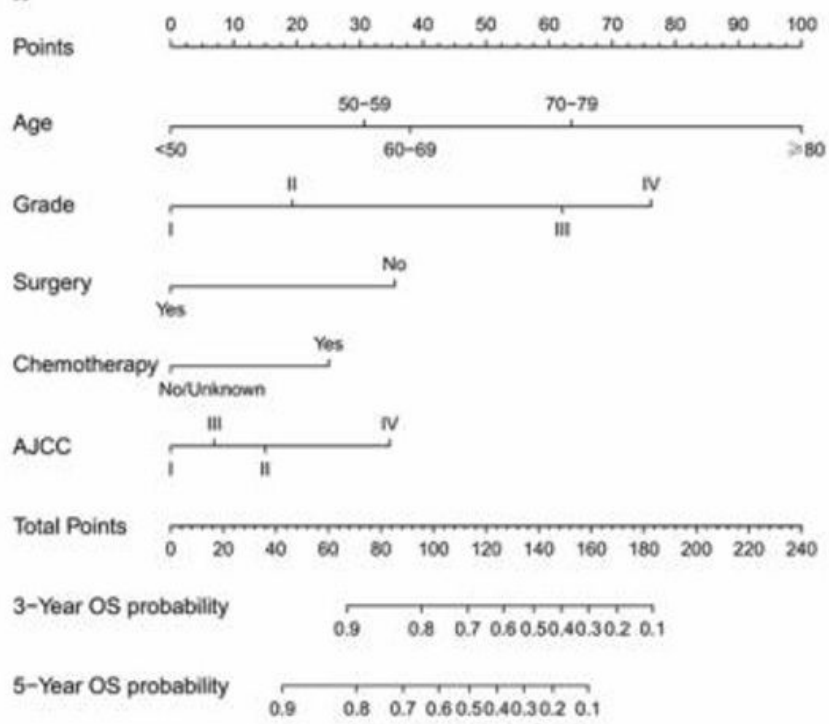

B

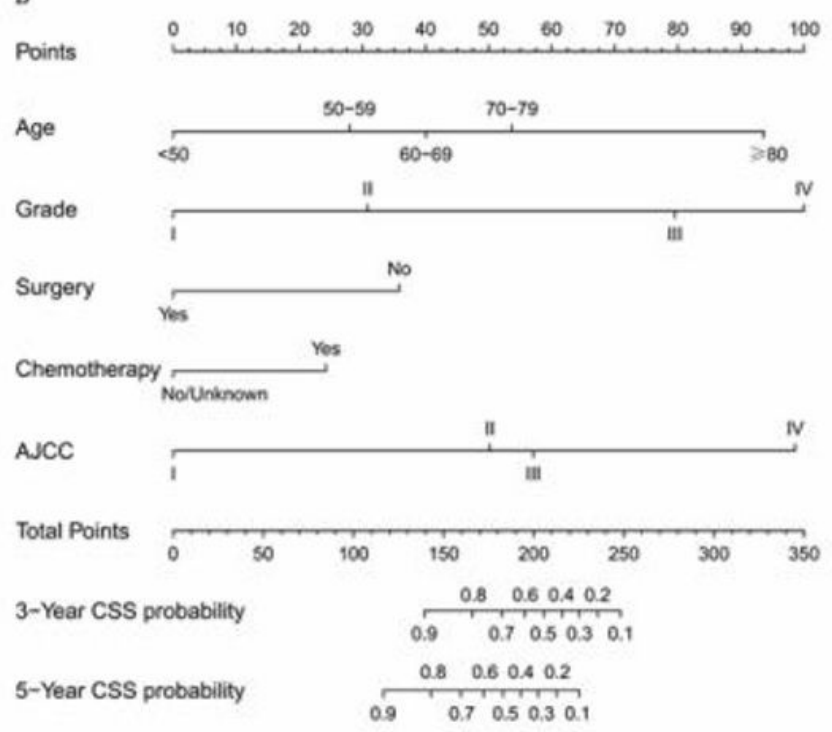

Figure 2

Nomograms predicting 3-, and 5-year OS (A) and CSS (B) of patients with small intestinal neuroendocrine carcinoma. 

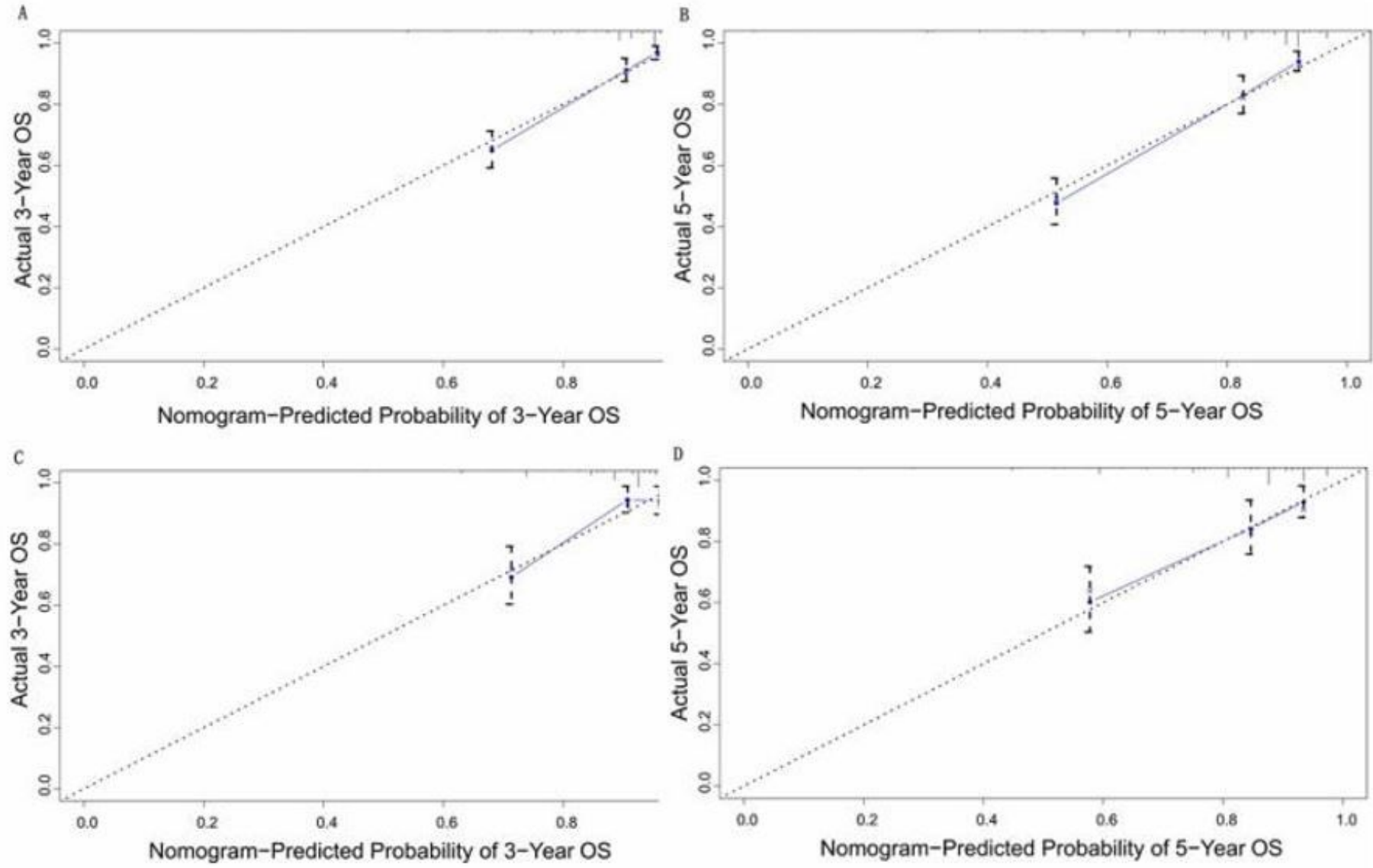

\section{Figure 3}

Calibration plots of the nomogram for 3-, and 5-year OS prediction of the training cohort (A-B) and internal validation cohort (C-D). 

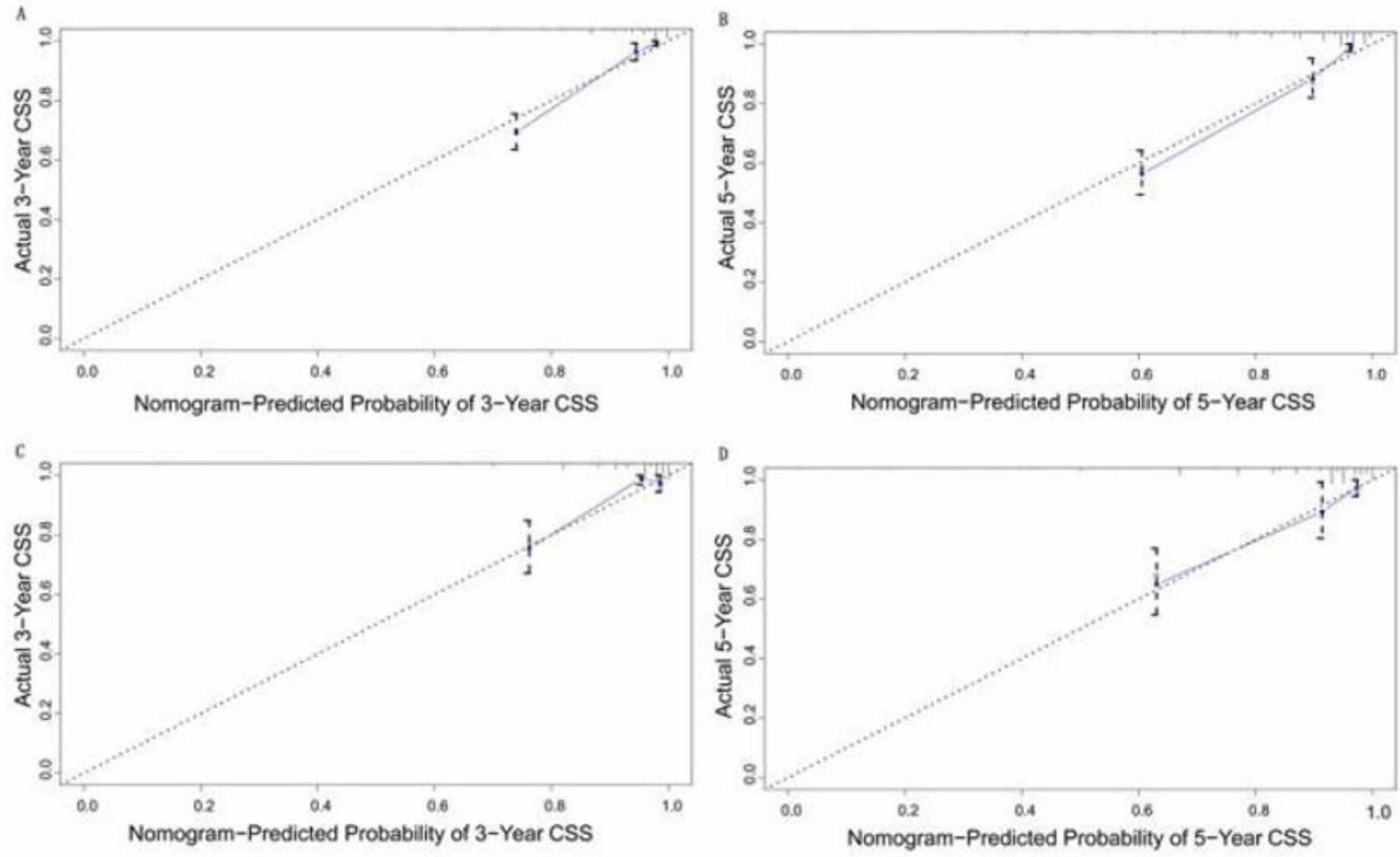

\section{Figure 4}

Calibration plots of the nomogram for 3-, and 5-year CSS prediction of the training cohort (A-B) and internal validation cohort $(C-D)$. 

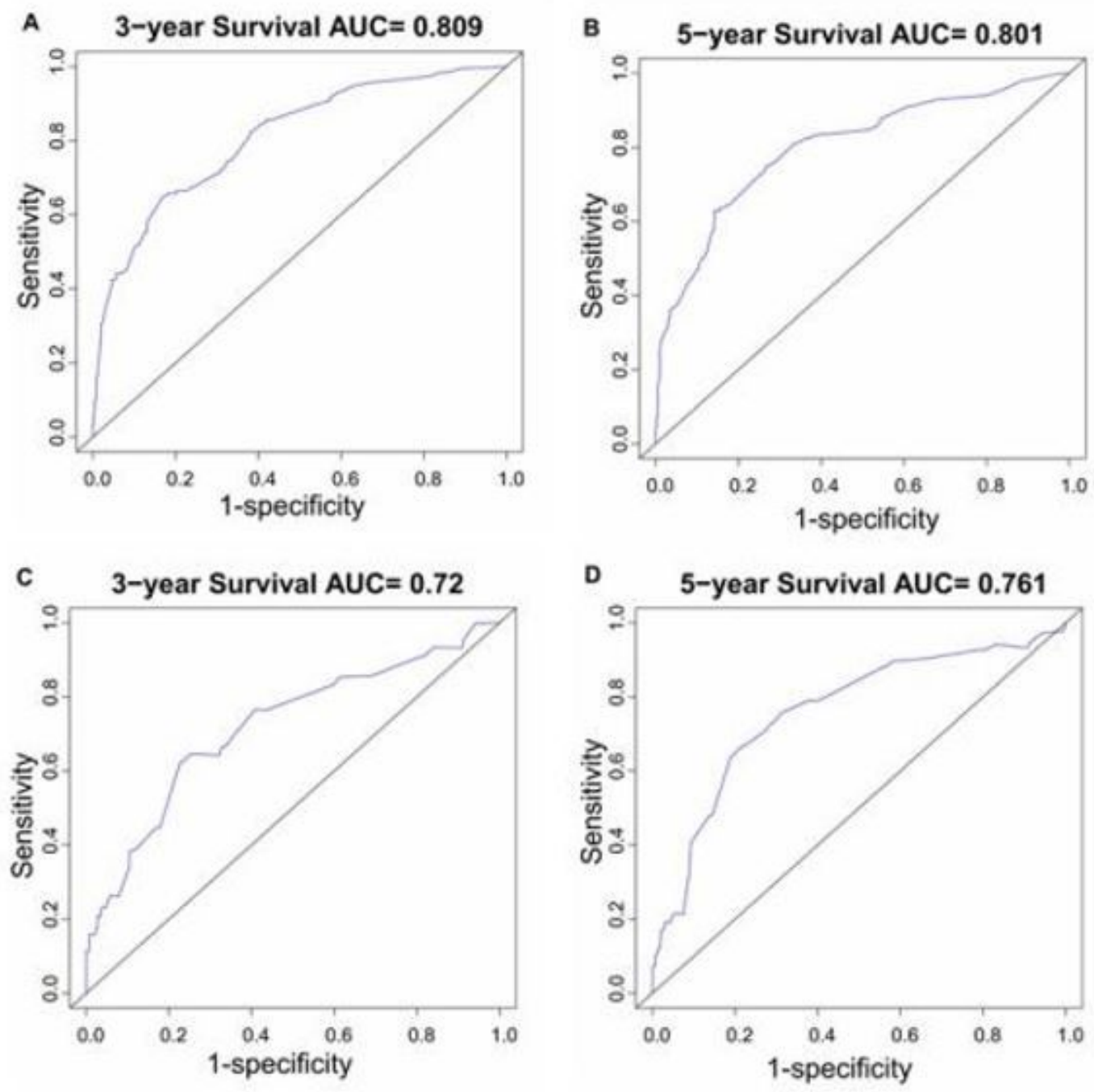

\section{Figure 5}

The ROC curves of the nomograms for 3-, and 5-year OS prediction of the training cohort (A-B) and internal validation cohort (C-D). 

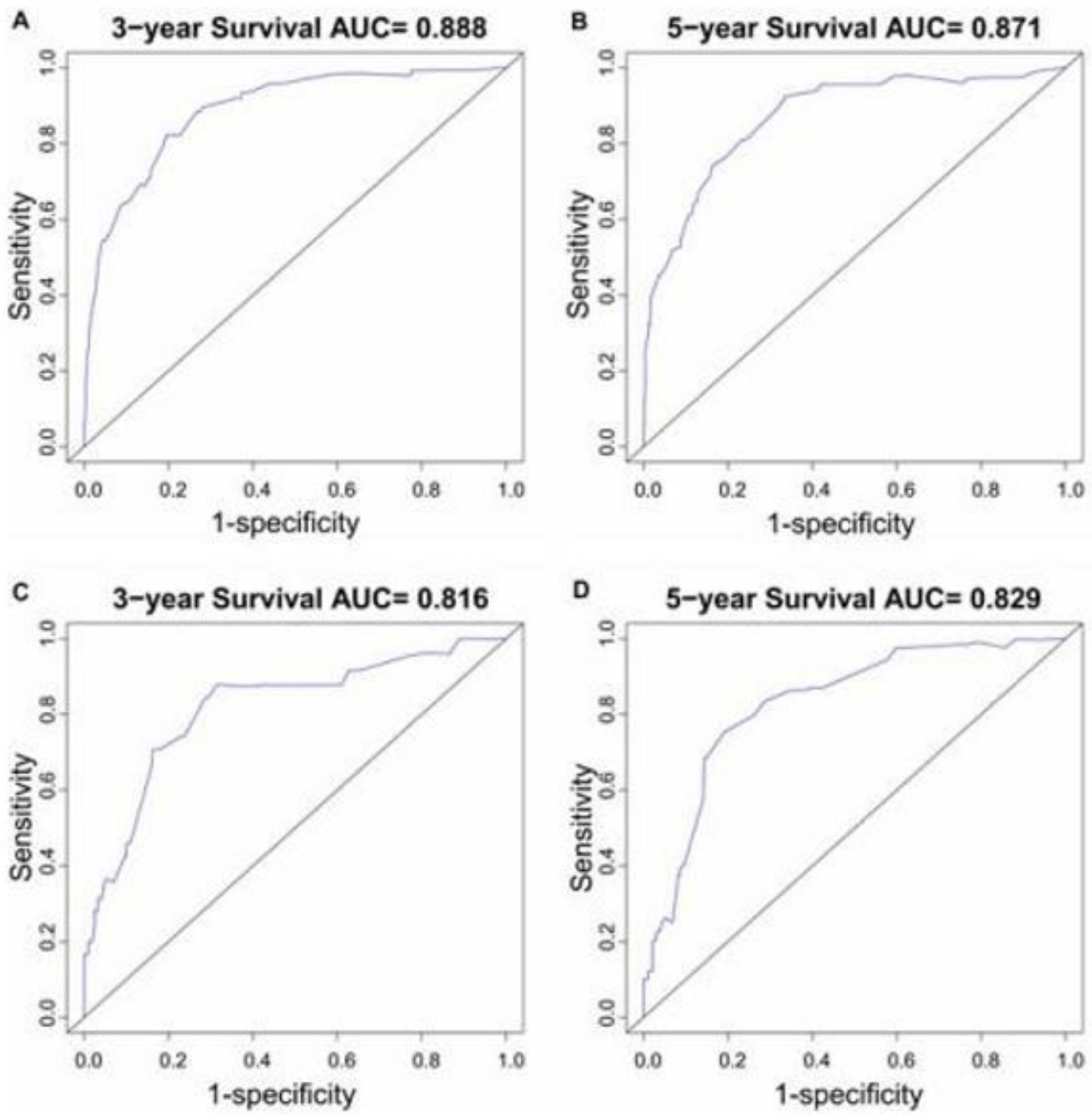

Figure 6

The ROC curves of the nomograms for 3-, and 5-year CSS prediction of the training cohort (A-B) and internal validation cohort (C-D). 